\title{
Changes in MCT 1, MCT 4, and LDH expression are tissue specific in rats after long-term hypobaric hypoxia
}

\author{
GRANT B. MCCLELLAND AND GEORGE A. BROOKS \\ Exercise Physiology Laboratory, Department of Integrative Biology, \\ University of California, Berkeley, California 94720
}

Received 23 October 2001; accepted in final form 3 December 2001

\begin{abstract}
McClelland, Grant B., and George A. Brooks. Changes in MCT 1, MCT 4, and LDH expression are tissue specific in rats after long-term hypobaric hypoxia. J Appl Physiol 92: 1573-1584, 2002. First published January 18, 2002; 10.1152/ japplphysiol.01069.2001.-Little is known about the effect of chronic hypobaric hypoxia on the enzymes and transporters involved in lactate metabolism. We looked at the protein expression of monocarboxylate transporters MCT 1, MCT 2, and MCT 4, along with total lactate dehydrogenase (LDH) and $\mathrm{LDH}$ isozymes in skeletal muscle, cardiac muscle, and liver. Expression of these components of the lactate shuttle affects the ability to transport and oxidize lactate. We hypothesized that the expression of MCTs and LDH would increase after acclimation to high altitude (HA). The response to acclimation to HA was, however, tissue specific. In addition, the response was different in whole muscle $(\mathrm{Mu})$ and mitochondria-enriched (Mi) fractions. Heart, soleus, and plantaris muscles showed the greatest response to HA. Acclimation resulted in a $34 \%$ increase in MCT 4 in heart and a decrease in MCT $1(-47 \%)$ and MCT $4(-47 \%)$ in plantaris $\mathrm{Mu}$. In Mi fractions, the heart had an increase $(+40 \%)$ and soleus a decrease $(-40 \%)$ in LDH. HA also had a significant effect on the $\mathrm{LDH}$ isozyme composition of both the Mu and $\mathrm{Mi}$ fractions. Mitochondrial density was decreased in both the soleus $(-17 \%)$ and plantaris $(-44 \%)$ as a result of chronic hypoxia. We conclude that chronic hypoxia had a tissuespecific effect on MCTs and LDH (that form the lactate shuttle) but did not produce a consistent increase in these components in all tissues.
\end{abstract}

monocarboxylate transporters; lactate dehydrogenase isozymes; lactate shuttle; lactate metabolism; high-altitude acclimation; cytochrome oxidase

THE CHANGES THAT OCCUR in gene and protein expression with long-term exposure to hypobaric hypoxia associated with high-altitude (HA) acclimation have received little attention. The effects of acute hypoxia exposure have been more extensively studied (23). For example, the machinery involved in carbohydrate metabolism, including membrane transporters and many glycolytic enzymes, is upregulated in skeletal muscle at the level of mRNA and proteins on acute exposure to low $\mathrm{O}_{2}(21$, 43). Whether the same is true after acclimation is unknown. Two recent studies suggest that changes in

Address for reprint requests and other correspondence: G. A. Brooks, 3060 Valley Life Sciences Bldg., Dept. of Integrative Biology, Univ. of California, Berkeley, Berkeley, CA 94720-3140 (E-mail: gbrooks@socrates.berkeley.edu). gene and protein expression may be attenuated in chronic hypoxia in skeletal muscle and brain $(16,41)$. Lactate is a metabolic intermediate with high turnover and oxidation rates that exceed those of glucose during exercise in rats $(11,18)$ and humans $(37)$. Moreover, its metabolism is affected by altitude exposure (9). Little is known with regard to the effects of chronic hypoxia on the expression of enzymes and transporters of lactate metabolism, but the response(s) may be tissue specific. For instance, red and white muscles have very different patterns of gene expression, even in normoxia (13), and respond to perturbations in energy balance in different ways.

Monocarboxylate transporters (MCTs) are transmembrane proteins that facilitate the transport of lactate in and out of cells (30). Two isoforms most commonly found in locomotory and cardiac muscle are MCT 1 and MCT 4. Also, the apparent $V_{\max }$ of lactate uptake reflects the density of MCTs, and MCT 1 expression is known to increase with contractile activity associated with exercise training or chronic electrical stimulation (e.g., Refs. 19, 40). This increase in MCT 1 expression is correlated with changes in mRNA, is highest in oxidative muscle fibers, and facilitates lactate uptake at the sarcolemmal and mitochondrial membranes $(3,5,8)$. MCT 4 expression does not change in concert with mRNA (5), MCT 4 is found predominantly in glycolytic fibers, and its putative role is lactate extrusion (17). The extent to which these transporters are affected by exposure to chronic hypoxia has never been documented. It is not known, for instance, whether they respond through a well-characterized induction pathway like other components of the glycolytic pathway $(21,43)$. MCT 2 , another isoform known to transport lactate, is found primarily in liver and brain (42). Little is known about the regulation of this isoform. An increase in its density, however, could enhance lactate transport for use as a gluconeogenic precursor in liver.

MCTs and lactate dehydrogenase (LDH) are involved in the shuttling of lactate between cells via the proposed cell-cell lactate shuttle (6). A proposed intracellular lactate shuttle directs endogenous lactate

The costs of publication of this article were defrayed in part by the payment of page charges. The article must therefore be hereby marked "advertisement" in accordance with 18 U.S.C. Section 1734 solely to indicate this fact. 
toward oxidation by mitochondria $(10,46)$. Consequently, changes in expression of shuttle machinery may affect the cellular transport and oxidation of lactate. For example, with endurance training in humans, there is a correlation between lower lactate release with higher MCT 1 content in mitochondria or sarcolemmal membranes (19). Therefore, changes in MCT expression with chronic hypoxia may shed some light on the well-documented alteration of lactate metabolism (reduced peak and submaximal exercise blood lactate concentrations) with the transition from acute to chronic hypoxia $(7,22)$. Because blood lactate concentrations ([lactate $]_{b}$ ) represent a balance between uptake and release by tissues, it is interesting that human skeletal muscles after acclimation become net lactate consumers during exercise (7). Whether this is due to changes in sarcolemmal or mitochondrial MCT 1 and/or $\mathrm{LDH}$ is not yet known. Lactate oxidation can also be enhanced by increasing mitochondrial membrane density and, therefore, associated transporters. Past findings in this area are varied, with hypoxia acclimation either decreasing (14), increasing (33), or not affecting $(28,35)$ mitochondrial density. Moreover, it is unknown whether hypoxia affects expression of mitochondrial components of the lactate shuttle, namely mitochondrial MCT 1 and $\mathrm{LDH}(\mathrm{mLDH})$. Also, the cellular distribution and composition of $\mathrm{LDH}$ isozymes may affect lactate kinetics at altitude. Measurement of these components will illuminate the role of the lactate shuttle before and after altitude acclimation.

In this study, we used HA-acclimated rats to test the hypothesis that chronic hypoxia will increase the expression of MCT 1 and LDH in oxidative muscle fibers. To look at the tissue specificity of this response, we examined these changes in four locomotory muscles, in cardiac muscle, and in liver.

\section{METHODS}

Animals. As part of a previous study (39), female Wistar rats (Charles River, St. Hyacinthe, QC, Canada) were randomly assigned to two groups, one kept under normoxic sea level (SL) conditions and the other under hypobaric hypoxia equivalent to 4,300 m HA. Each group had free access to food and water as well as a water supplement (Transgel, Charles River). The HA rats were acclimated by progressively decreasing the chamber pressure over a 10-day period to a final pressure of $450 \mathrm{mmHg}$, as described before (38). The acclimation period was 8 wk. Average weights for the two groups used in this study were $230 \pm 4 \mathrm{~g}$ for SL controls and $236 \pm$ $5 \mathrm{~g}$ for acclimated (HA) rats.

Tissue sampling. As part of the previous study (39), rats were exercised twice, $48 \mathrm{~h}$ apart, for $60 \mathrm{~min}$ at $60 \%$ maximal $\mathrm{O}_{2}$ uptake $(12.3 \pm 0.1 \mathrm{~m} / \mathrm{min})$ under normoxia. At the end of the second exercise bout, they were quickly euthanized ( 20 $\mathrm{mg} / 100 \mathrm{~g}$ pentobarbital sodium) via a previously implanted arterial catheter. Right and left hindlimb muscles (soleus, plantaris, red and white gastrocnemius), liver, and heart were removed and quickly frozen by use of liquid $\mathrm{N}_{2}$-cooled aluminum tongs and then submerged in liquid $\mathrm{N}_{2}$ before storage at $-80^{\circ} \mathrm{C}$ until analysis. Visual inspection did not reveal any obvious differences in daily activity between HA and SL rats. Both groups performed the same acute exercise in normoxia, and this may have some impact on the results but is unlikely to affect HA-to-SL comparisons.

Sample preparation. Homogenates were prepared as previously described (19) with some modification. Briefly, tissues were homogenized by using a motorized glass homogenizer at $4^{\circ} \mathrm{C}$ in buffer containing $210 \mathrm{mM}$ sucrose, $2 \mathrm{mM}$ EGTA, 40 $\mathrm{mM} \mathrm{NaCl}$, and $30 \mathrm{mM}$ HEPES at pH 7.4 (buffer A), supplemented with $0.15 \%$ protease inhibitor cocktail (Sigma Chemical). Total muscle homogenate was prepared by centrifugation at $600 \mathrm{~g}$ for $10 \mathrm{~min}$. One milliliter was removed, and, after dilution ( $0.75 \times$ total volume) with buffer containing $1.167 \mathrm{M} \mathrm{KCl}$ and $58.3 \mathrm{mM} \mathrm{Na}_{4} \mathrm{P}_{2} \mathrm{O}_{7} \cdot 10 \mathrm{H}_{2} \mathrm{O}, \mathrm{pH} 7$ (buffer $B$ ), the homogenates were centrifuged at $230,000 \mathrm{~g}$ for $120 \mathrm{~min}$. The pellet was resuspended in buffer consisting of $1 \mathrm{mM}$ EDTA and $10 \mathrm{mM}$ Tris at $\mathrm{pH} 7.4$ (buffer C). One-third volume of $16 \%$ SDS was added to the resulting suspension and centrifuged at room temperature for $25 \mathrm{~min}$ at $1,000 \mathrm{~g}$, resulting in a supernatant containing whole muscle membrane preparations $(\mathrm{Mu})$. To separate mitochondrial fractions, the remaining original homogenate (after $600 \mathrm{~g}$ spin) was centrifuged at $10,000 \mathrm{~g}$ for $20 \mathrm{~min}$ at $4^{\circ} \mathrm{C}$. This pellet was resuspended in buffer $C$ as above, and aliquots of the supernatant, before the addition of SDS, were saved for LDH isozyme measurements. The remaining solution was mixed with one-third volume of $16 \%$ SDS and then treated like Mu homogenates and represents mitochondria-rich fractions (Mi). Purity of mitochondrial fractions was confirmed in preliminary experiments by the absence of GLUT1 reactivity in immunoblots. The supernatant was diluted with 0.75 volume of buffer $B$ and spun at $230,000 \mathrm{~g}$. Aliquots of the resulting supernatant were collected as pure cytosol $(\mathrm{Cy})$, lacked SDS, and were used for LDH isozyme measurements. All of the resulting homogenates were aliquoted and frozen at $-80^{\circ} \mathrm{C}$.

RBC membrane "ghosts." Red blood cell (RBC) membrane "ghosts" were used as a positive control for MCT 1 immunoblotting. Whole blood from a donor rat (Sprague-Dawley, UCB) was anticoagulated by mixing with seven volumes of acid-citrate-dextrose buffer containing $75 \mathrm{mM}$ sodium citrate, $38 \mathrm{mM}$ citric acid, and $138 \mathrm{mM}$ D-glucose. At $4^{\circ} \mathrm{C}$, blood was mixed with sedimenting buffer (1:4 vol/vol, $\mathrm{pH} 7.5)$ consisting of $150 \mathrm{mM} \mathrm{NaCl}$ and $5 \mathrm{mM}$ sodium phosphate. The RBCs were allowed to settle out for 1-2 h. After being washed three times with physiological saline, they were centrifuged at $2,000 \mathrm{~g}$ for $5 \mathrm{~min}$. Cells were lysed by rapid addition of $10 \mathrm{vol}$ of a $\mathrm{pH} 7.5$ buffer consisting of $7.5 \mathrm{mM}$ sodium phosphate and $1 \mathrm{mM}$ EDTA containing protease inhibitors (antipain at $2 \mu \mathrm{g} / \mathrm{ml}$ ). The lysed cells were centrifuged at $37,000 \mathrm{~g}$ for $10 \mathrm{~min}$ at $4^{\circ} \mathrm{C}$, and the resulting pellet was washed with lysing buffer until white in appearance. The "ghosts" were divided into aliquots and stored at $-80^{\circ} \mathrm{C}$ for future use.

Immunoblotting. Custom polyclonal antibodies to MCT 1 and MCT 4 from rabbit were used; their specificities have been confirmed elsewhere (8). Rat RBC membrane ghosts were used as a positive control for MCT 1 with an arbitrary unit of MCT set at $0.25 \mu \mathrm{g}$ of RBC protein. Chicken anti-MCT 2 antibody (Chemicon International) was used to probe liver homogenates. Mitochondrial density was estimated by using a monoclonal mouse anti-cytochrome oxidase against the IV subunit of cytochrome oxidase (COX; Molecular Probes). LDH antibodies were polyclonal specific to the whole enzyme (not subunit specific) in rabbit (Rockland). Secondary antibodies were donkey anti-rabbit (MCT 1 and 4) and sheep anti-mouse (COX, Amersham), anti-goat (LDH, Santa Cruz), and anti-chicken (MCT 2, Chemicon International) horseradish peroxidase-linked monoclonal antibodies. Protein content of each sample was determined by the bicinchoninic acid 
assay (Pierce), using BSA as a standard. Equal amounts of protein were separated on $10 \%$ SDS-PAGE and transferred by electroblotting onto polyvinylidene difluoride membranes (Invitrogen). Membranes were incubated for $1 \mathrm{~h}$ at room temperature or overnight at $4^{\circ} \mathrm{C}$ in $10 \%$ blocking buffer [150 $\mathrm{mM} \mathrm{NaCl}, 0.1 \%$ Tween 20, and $50 \mathrm{mM}$ Tris, $\mathrm{pH} 7.5$ (TTBS), $10 \%$ nonfat dried milk] before incubation with antibodies for $2 \mathrm{~h}$ at room temperature or overnight at $4^{\circ} \mathrm{C}$ in $5 \%$ blocking buffer (in Tris-buffered saline). Membranes were washed once for $15 \mathrm{~min}$ and then twice for $5 \mathrm{~min}$ in TTBS and then incubated for $90 \mathrm{~min}$ at room temperature with secondary antibody in Tris-buffered saline. Membranes were washed as above, and protein expression was then detected by enhanced chemiluminescence by standard methods (Renaissence; NEN). Autoradiographic films (Kodak X-Omat Blue XB-1) were exposed to membranes and developed (Konica QX-130A Plus). Band densities were determined with a Bio-Rad GS700 densitometer and quantified by using Molecular Analyst software (Bio-Rad Laboratories). Molecular weight standards were used to identify appropriate antibody binding (Rainbow Marker, Amersham Life Sciences). The membranes were stripped of antibody signal by a Western blot recycling kit (Alpha Diagnostic International) and washed with TTBS before being reprobed. Complete stripping of signal was verified in preliminary experiments by the absence of signal after membranes were treated with enhanced chemiluminescence and processed as above.

LDH isozymes. The cellular composition of $\mathrm{LDH}$ isozymes (LDH 1-5) was evaluated in Cy and Mi fractions. Protein (1.5 $\mu \mathrm{g}$ Cy or $10 \mu \mathrm{g} \mathrm{Mi}$ ) was loaded onto $1 \%$ agarose gels (Reliant precast gels; FMC) and separated for $60 \mathrm{~min}$ at $100 \mathrm{~V}$ by using $2 \mu \mathrm{l}$ of isotrol (Sigma Chemical) as an internal positive control. Bands representing the different isozymes were revealed colorimetrically (Sigma Chemical procedure 705), and the gels were fixed with $5 \%$ acetic acid. The resulting bands were quantified as described above for Western blots. When a band was not detected, it was given a value of $0 \%$ but may have been below the detection limits of the assay.

Statistics. Results were analyzed by using a $t$-test, and linear regressions were tested by using an ANOVA $(P<$ $0.05)$. All percentages were arcsine-square-root transformed. When tests for normality failed, a Mann-Whitney rank-sum test was used. All the values presented are means $\pm \mathrm{SE}$.

\section{RESULTS}

$M C T$ 1, MCT 4, and LDH expression. Protein expression was determined by Western blot techniques; representative blots are shown in Fig. 1. The expression of MCT 1 was not affected by chronic hypoxia in heart, soleus, or red gastrocnemius $\mathrm{Mu}$ or $\mathrm{Mi}$ fractions $(P>$ 0.05 , Figs. $2, A$ and $E ; 3, A$ and $E$; and $4, A$ and $E)$. MCT 4 expression, in contrast, was increased by $34 \%$ in heart $\mathrm{Mu}$ preparations but not in other oxidative tissues. Moreover, total LDH expression was affected by chronic hypoxia differently in heart (increased, $+40 \%$ ) and soleus (decreased, $-40 \%$ ) mitochondria (Figs. $2 F$ and $3 F$ ). Also, there was a positive and significant correlation between MCT 1 and LDH in heart Mu $\left(r^{2}=\right.$ $0.90, P<0.001)$ as well as a positive correlation between MCT 1 and COX in soleus $\left(r^{2}=0.35, P<0.03\right)$. Acclimation had no significant effect on the expression of these variables in the red gastrocnemius muscle (Fig. 4). Chronic hypoxia had its most pronounced effect on the mixed muscle plantaris. In this muscle
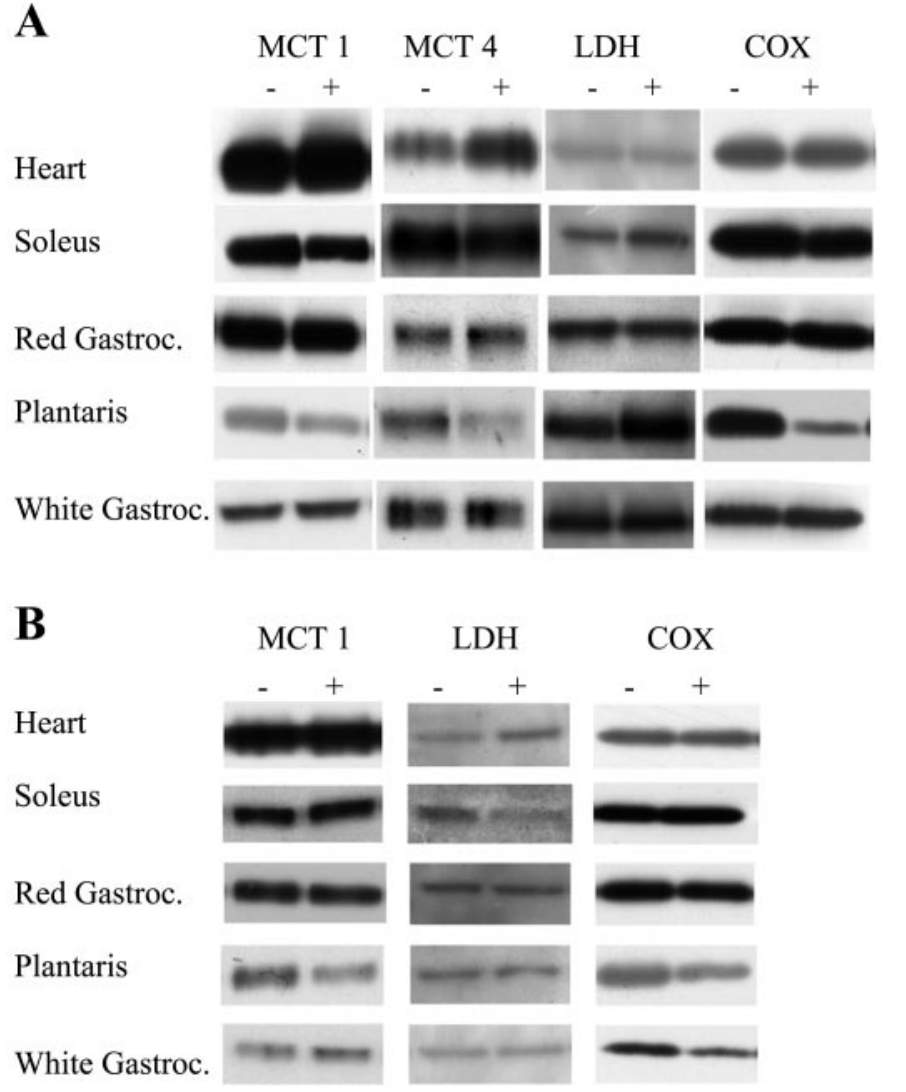

Fig. 1. Representative Western blots showing amounts of monocarboxylate transporters (MCT) 1 and 4, lactate dehydrogenase (LDH), and cytochrome oxidase $(\mathrm{COX})$ in whole muscle $(\mathrm{Mu} ; A)$ and mitochondrial $(\mathrm{Mi} ; B)$ fractions in heart, soleus, red gastrocnemius (Gastroc.), plantaris, and white gastrocnemius muscle (liver not shown) in sea level (SL) control (-) and high-altitude (HA) acclimated (+) female Wistar rats.

there was a large decrease in the expression of MCT 1 $(-47 \%)$ and MCT $4(-47 \%)$ in Mu preparations (Fig. 5, $A$ and $B, P<0.05)$. LDH showed a nonsignificant increase with altitude acclimation, and this led to a significantly negative correlation between MCT 1 and $\mathrm{LDH}$ in this muscle $\left(r^{2}=0.42, P=0.01\right)$. The more glycolytic white gastrocnemius, on the other hand, showed no response to chronic hypoxia acclimation. Also, there was no significant correlation between $\mathrm{LDH}$ and MCT 4 content in the muscles studied (data not presented).

Changes in aerobic capacity. Expression of COX, used as an index of tissue aerobic ability and mitochondrial density, was decreased after altitude acclimation in both the soleus $(-17 \%)$ and plantaris $(-44 \%)$ muscles. Other tissue showed no change in COX expression in the $\mathrm{Mu}$ fraction (Figs. $2 G-7 G$ ). There was also no change in the COX content per gram of mitochondrial protein as demonstrated in the Mi fractions (Figs. $2 G-7 G)$.

$L D H$ isozymes. The distribution of the five different $\mathrm{LDH}$ isozymes consisting of combinations of the two subunits LDH A (M type) and LDH B (H type) were measured by gel electrophoresis. The five isozymes are 
Fig. 2. Expression of MCT 1 ( $A$ and $E$ ), MCT $4(B), \mathrm{LDH}(C$ and $F)$, and COX $(D$ and $G)$ in heart $\mathrm{Mu}$ and $\mathrm{Mi}$ cell fractions in rats before (SL) and after (HA) long-term acclimation to hypobaric hypoxia; $n=8$ for HA and $n=6$ for SL. * Significantly different from SL controls $(P<0.05)$.
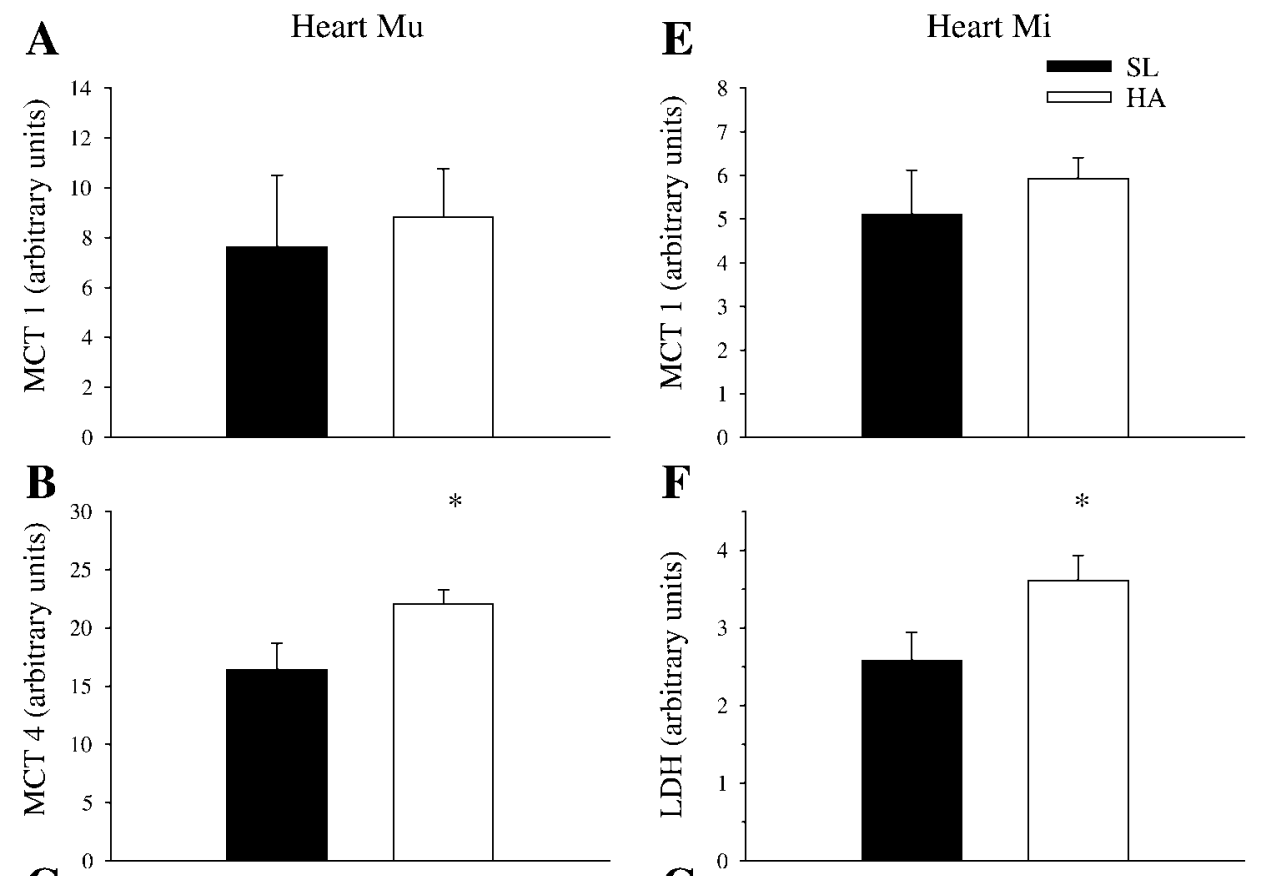

C
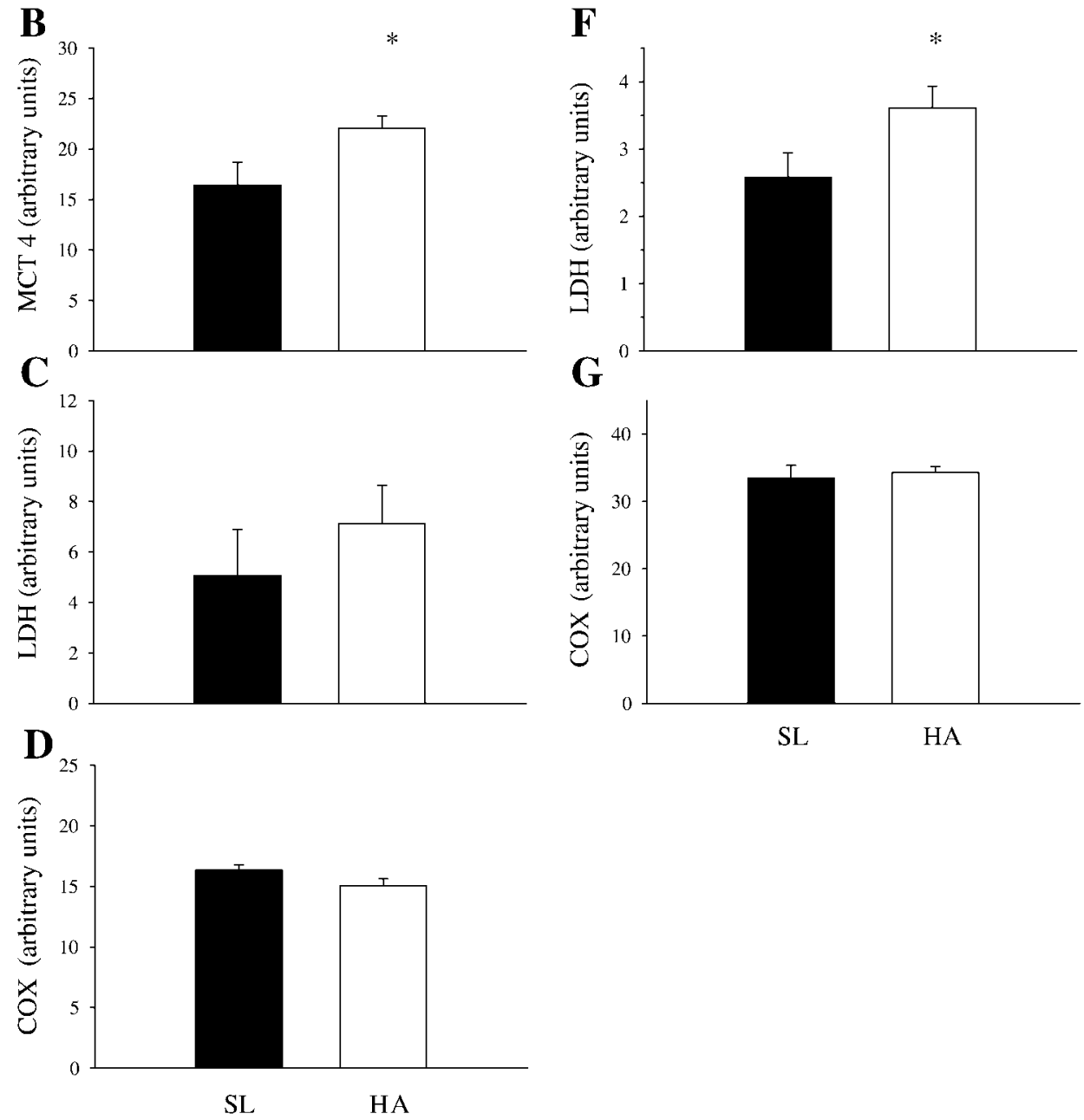

LDH5 $\left(\mathrm{A}_{4}\right), \mathrm{LDH} 4\left(\mathrm{~A}_{3} \mathrm{~B}_{1}\right), \mathrm{LDH} 3\left(\mathrm{~A}_{2} \mathrm{~B}_{2}\right), \mathrm{LDH} 2\left(\mathrm{~A}_{1} \mathrm{~B}_{3}\right)$, and LDH1 $\left(\mathrm{B}_{4}\right)$. The isozyme distribution for $\mathrm{LDH}$ in the $\mathrm{Cy}$ and $\mathrm{Mi}$ fractions of the tissue studied appears in Table 1. In all of the tissues studied from SL and HA individuals, there was a significant difference in $\mathrm{LDH}$ isozyme composition between the cytosol and mitochondria. There were also significant differences in the responses of these two cellular fractions to altitude acclimation. Heart and red gastrocnemius Mi fractions showed a decrease in LDH4. The heart Mi also showed an increase in LDH1 with acclimation to altitude $(P<$ 0.05 ) (Table 1). This was reflected in a significant increase in the percentage of LDH B subunits in heart
Mi fractions from HA rats (Table 2). The Mi fractions were higher than Cy in LDH A subunits in all tissues except soleus (Table 2).

\section{DISCUSSION}

This is the first study to examine the effects of acclimation to chronic hypoxia on the expression of MCTs. It is also the first attempt to study the effects of hypoxia on the cellular components of the lactate shuttle. Acclimation to chronic hypobaric hypoxia elicits its effects in a tissue-specific manner. The heart (Fig. 2) and plantaris (Fig. 5) show profound plasticity to ac- 

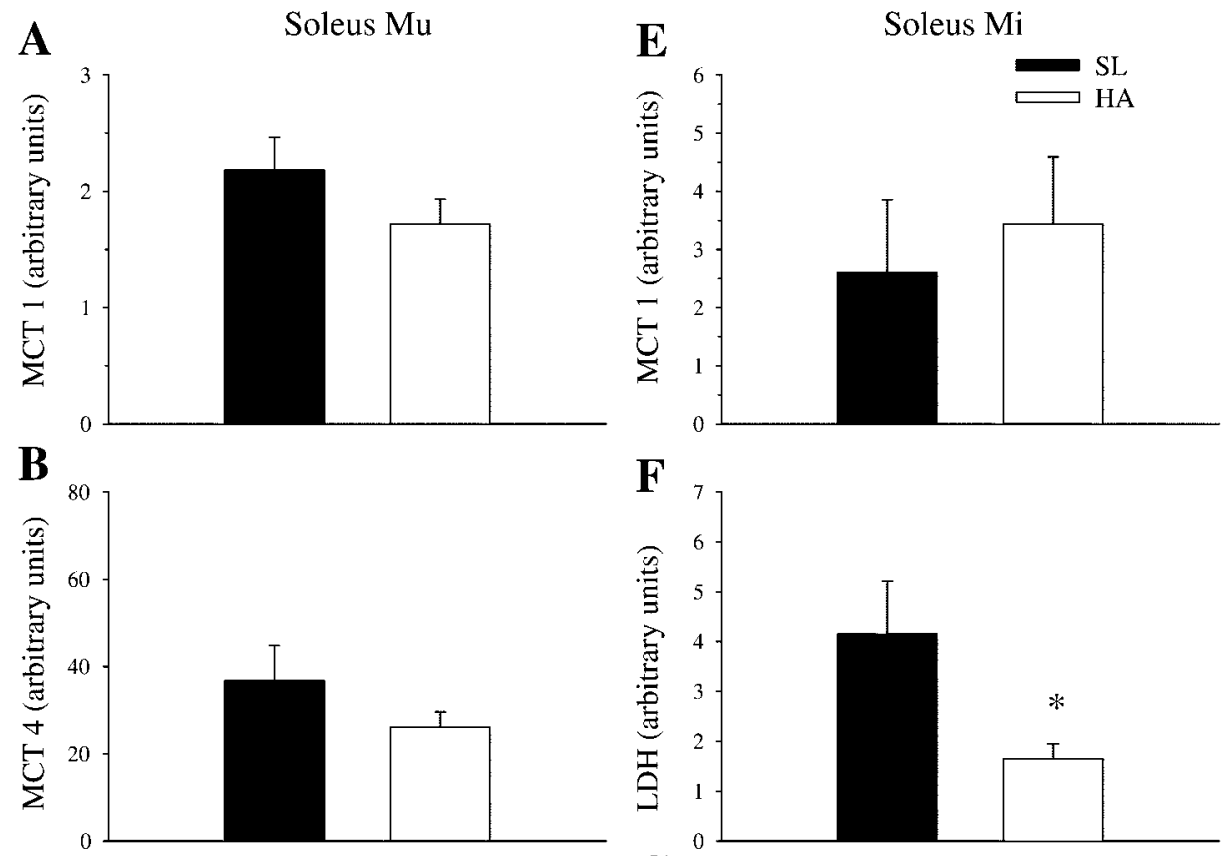

Fig. 3. Expression of MCT 1 ( $A$ and $E$ ), MCT $4(B), \mathrm{LDH}(C$ and $F)$, and COX $(D$ and $G$ ) in soleus $\mathrm{Mu}$ and $\mathrm{Mi}$ cell C

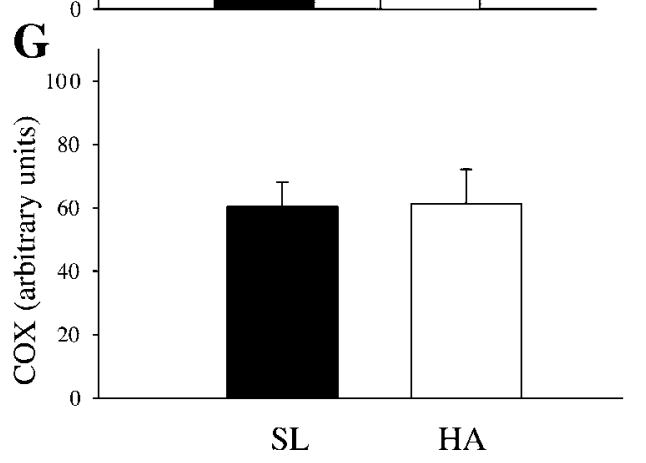
fractions in SL and HA; $n=8$ for HA and $n=6$ for SL. * Significantly different from SL controls $(P<0.05)$.

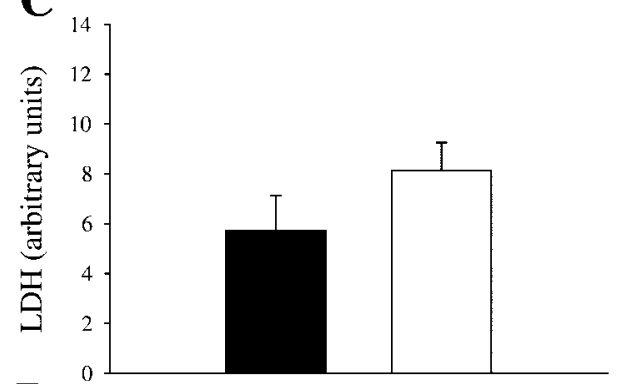

D

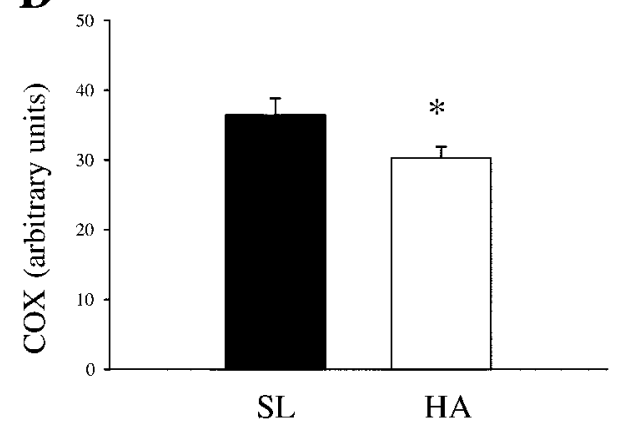

climation, whereas liver (Fig. 7) along with red (Fig. 4) and white (Fig. 6) gastrocnemius muscles show no significant response to this treatment. Moreover, hypoxia can elicit changes independently in the cytosol and mitochondria. The expression of MCT 1 and MCT 4 is regulated in different ways by hypoxia depending on the tissue. MCT 4 protein was increased in the heart (Fig. $2 B$ ), but acclimation resulted in a large decrease in the plantaris (Fig. $5 B$ ). The tissue specificity of this response to chronic hypoxia rules out a coordinated response by the machinery involved in lactate metabolism. Although some tissues may be able to increase their lactate uptake and oxidation, others show a decrease in transporters, enzymes, and mitochondrial density. These results do not provide direct evidence for increased ability for uptake and oxidation of lactate as an explanation for the previously reported (32) perturbation caused by chronic hypoxia on lactate kinetics.

Chronic hypoxia and protein expression. Chronic hypoxia and its effects on the expression of genes and gene products involved in energy metabolism are underexplored. Here we find that acclimation to a simulated altitude $(4,300 \mathrm{~m})$ had a tissue-specific effect on protein expression. This is perhaps not surprising considering that, in the absence of experimental perturbations, red and white muscles show distinctly different gene expression patterns (13). Moreover, many pro- 
Fig. 4. Expression of MCT 1 ( $A$ and $E$ ), MCT $4(B), \mathrm{LDH}(C$ and $F)$, and $\operatorname{COX}(D$ and $G$ ) in red gastrocnemius $\mathrm{Mu}$ and $\mathrm{Mi}$ cell fractions in SL and HA rats; $n=8$ for HA and $n=6$ for SL.
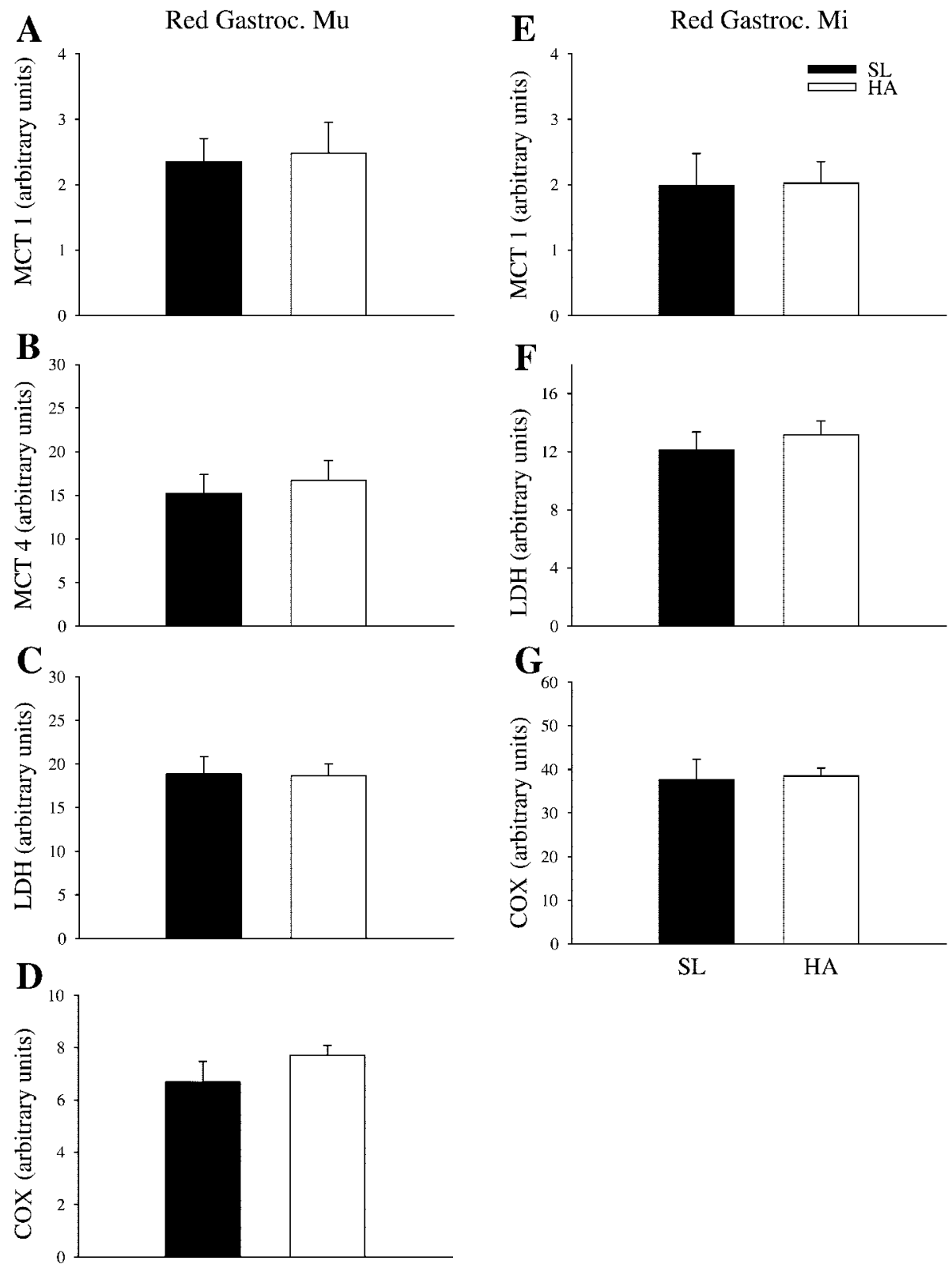

SL HA

teins, including LDH A $(21,26,43)$, show isozyme- and isoform-specific regulation of expression with acute hypoxia. These genes are regulated through the wellcharacterized hypoxia-inducible factor-1 acting on a hypoxia response element of their respective genes (44). There is no present evidence that the genes encoding MCT 1, 2, or 4 contain sequences binding hypoxia-inducible factor or any other factor. However, differences in MCT's response to hypoxia may reflect differences in some other promoters. Interestingly, the response for one of these isoforms (MCT 4) is in opposing directions depending on the tissue examined.

Changes in LDH isozyme composition (Table 1) demonstrate that the two genes encoding subunits A (M type) and B (H type) respond differently to hypoxia.
Transcription of LDH A is known to be upregulated by acute hypoxia (26), whereas LDH B generally shows no response to hypoxia $(21,25)$. We confirm here that chronic hypoxia affects the differential expression of $\mathrm{LDH}$ isozymes (25). The ultimate consequences of these differences after acclimation are uncertain because the metabolic significance of $\mathrm{LDH}$ isozyme changes in relation to reaction kinetics have recently been questioned (24).

For the first time, the effects of hypoxia on isozymic composition of $\mathrm{mLDH}$ were measured (Table 1). Acclimation had a significant effect on $\mathrm{mLDH}$, shifting the pattern of isozymes in heart and red gastrocnemius $\mathrm{Mi}$ fractions. Interestingly, in heart mitochondria there was a shift toward a greater percentage of $\mathrm{LDH} B$ 

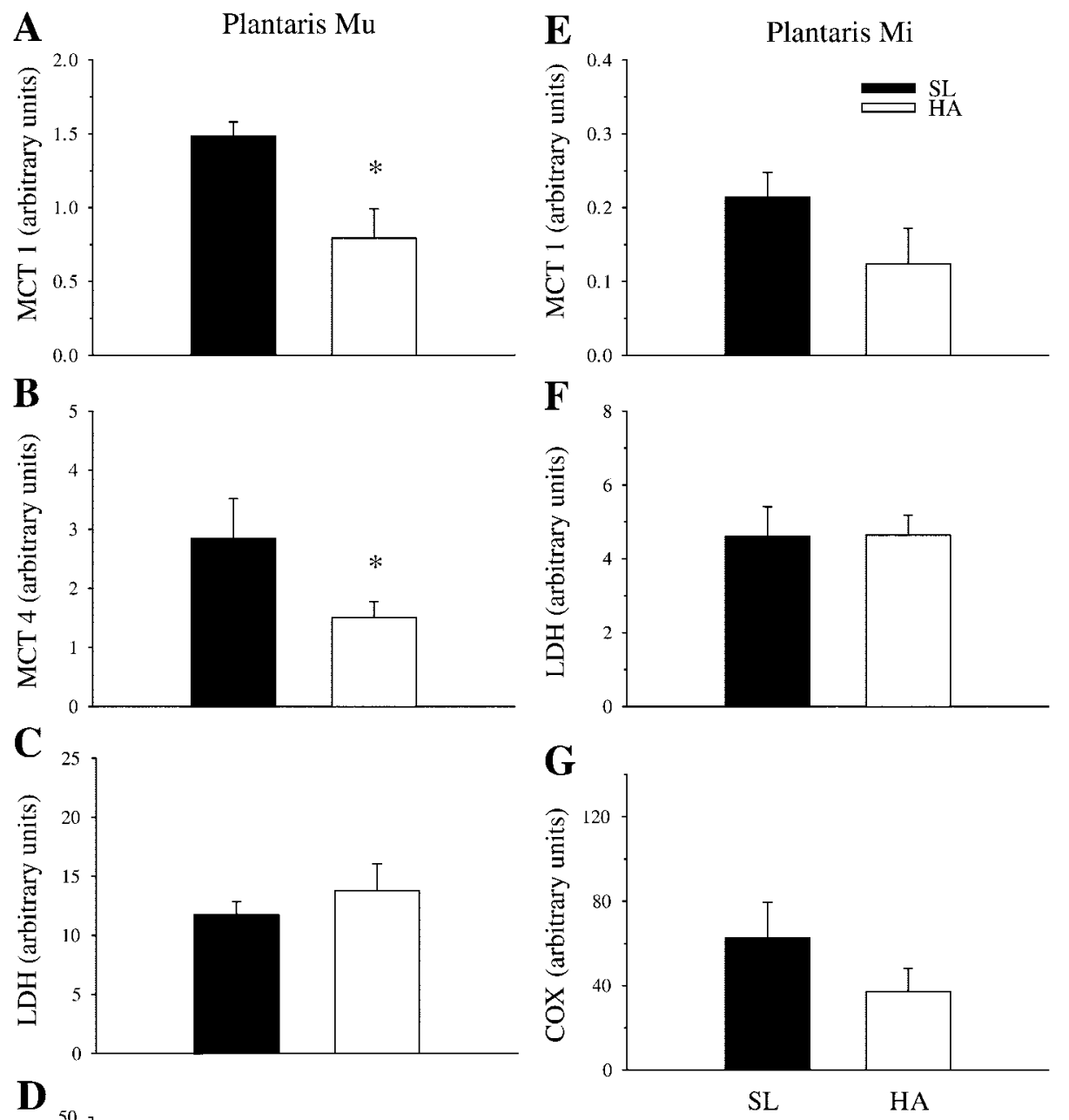

Fig. 5. Expression of MCT 1 ( $A$ and $E$ ), MCT $4(B), \mathrm{LDH}(C$ and $F)$, and $\mathrm{COX}(D$ and $G$ ) in plantaris $\mathrm{Mu}$ and $\mathrm{Mi}$ cell fractions in SL and HA rats; $n=8$ for HA and $n=6$ for SL. * Significantly different from SL controls $(P<0.05)$.

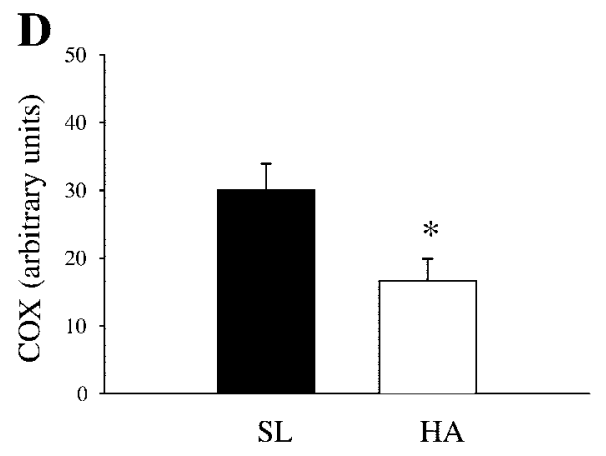

subunits (Table 2), normally found to be insensitive to hypoxia $(21,25)$. This occurred in the absence of MCT 1 changes in mitochondrial membranes (see MCTs below).

Expression of COX was reduced in some of the tissues examined (soleus and plantaris, Figs. $3 D$ and $5 D$ ). This is consistent with cell line work in which mRNA of COX subunit III and other mitochondria transcripts were reduced after 16 and $48 \mathrm{~h}$ of hypoxia (21). Other HA acclimation studies sampled mixed muscle or looked at single specific muscles and found a variety of results $(14,28,33,34)$. Any changes seen in this study are probably not the result of changes in myosin isoforms that are fairly insensitive to acclimation in $\operatorname{rats}(1)$.
Changes in mRNA expression of MCTs have been measured neither after acute nor after chronic hypoxia. Differences in the regulation of MCT 1 and MCT 4 have been noted in exercise training studies (5). The differential response of these two isoforms, even in the same muscles, of acclimated rats (e.g., Fig. 2) suggests that they are regulated through different mechanisms by hypoxia as well. Also, the possibility that MCTs undergo posttranslational modification has not been explored.

MCTs. The expression of MCTs in muscle is malleable, as shown by several studies on electrical stimulation, exercise training, limb unweighting, and addition of a $\beta_{2}$-receptor agonist (e.g., Refs. 5, 19, 20, 36). This first study to examine the expression of MCTs with 
Table 1. LDH isozyme composition (\% total) in the Cy and Mi fractions of heart, liver, and skeletal muscle of rats before and after acclimation to high-altitude hypoxia

\begin{tabular}{|c|c|c|c|c|c|c|c|c|c|c|}
\hline Tissue & \multicolumn{2}{|c|}{ LDH5 } & \multicolumn{2}{|c|}{ LDH4 } & \multicolumn{2}{|c|}{ LDH3 } & \multicolumn{2}{|c|}{ LDH2 } & \multicolumn{2}{|c|}{ LDH1 } \\
\hline \multicolumn{11}{|l|}{ Heart } \\
\hline $\mathrm{Mi}$ & $2.2 \pm 0.4 \dagger$ & $3.5 \pm 0.9 \dagger$ & $9.5 \pm 0.8 \dagger$ & $4.9 \pm 0.6^{*}$ & $21.1 \pm 0.9$ & $17.3 \pm 1.0^{*}$ & $37.0 \pm 1.9 \dagger$ & $36.7 \pm 1.1$ & $30.2 \pm 3.0$ & $37.6 \pm 1.6^{*}$ \\
\hline \multicolumn{11}{|l|}{ Soleus } \\
\hline $\mathrm{Cy}$ & $1.9 \pm 0.9$ & $5.9 \pm 2.6$ & $3.4 \pm 1.0$ & $3.0 \pm 0.8$ & $12.2 \pm 1.1$ & $11.2 \pm 0.7$ & $35.3 \pm 0.6$ & $34.5 \pm 1.3$ & $47.3 \pm 2.4$ & $45.4 \pm 2.7$ \\
\hline $\mathrm{Mi}$ & $78.3 \pm 3.8 \dagger$ & $79.2 \pm 3.6 \dagger$ & $2.0 \pm 0.5 \dagger$ & $0.8 \pm 0.6^{* \dagger}$ & $4.2 \pm 0.9$ & $4.1 \pm 0.7$ & $7.4 \pm 1.3$ & $7.2 \pm 1.4$ & $8.1 \pm 1.8$ & $8.8 \pm 1.5 \dagger$ \\
\hline \multicolumn{11}{|l|}{ Plantaris } \\
\hline $\mathrm{Cy}$ & $73.9 \pm 3.2$ & $64.4 \pm 7.5$ & $10.4 \pm 2.6$ & $13.9 \pm 1.5$ & $6.0 \pm 0.6$ & $7.6 \pm 0.6$ & $5.2 \pm 1.5$ & $7.7 \pm 0.8$ & $4.5 \pm 1.9$ & $6.3 \pm 1.6$ \\
\hline $\mathrm{Mi}$ & $74.2 \pm 8.6$ & $84.0 \pm 3.8$ & $9.8 \pm 4.4$ & $7.4 \pm 2.2$ & $7.2 \pm 1.3$ & $4.2 \pm 0.6 \dagger$ & $6.7 \pm 2.7$ & $3.0 \pm 0.7 \dagger$ & $2.1 \pm 1.7$ & $1.5 \pm 0.5$ \\
\hline \multicolumn{11}{|l|}{ WG } \\
\hline $\mathrm{Cy}$ & $96.9 \pm 0.4$ & 100 & $1.8 \pm 0.3$ & & $0.8 \pm 0.3$ & & $0.5 \pm 0.1$ & & $0.02 \pm 0.01$ & \\
\hline
\end{tabular}

Values are means \pm SE. Cy and Mi, cytosolic and mitochondrial fractions, respectively; LDH, lactate dehydrogenase. SL and HA, before $(n=6)$ and after $[n=8$ except for plantaris $(n=3)]$ acclimation to high-altitude hypoxia, respectively. LDH5 = $\mathrm{A}_{4}, \mathrm{LDH}_{4}=\mathrm{A}_{3} \mathrm{~B}_{1}$, $\mathrm{LDH} 3=\mathrm{A}_{2} \mathrm{~B}_{2}, \mathrm{LDH} 2=\mathrm{A}_{1} \mathrm{~B}_{3}$, and $\mathrm{LDH} 1=\mathrm{B}_{4} ; \mathrm{RG}$, red gastrocnemius; WG, white gastrocnemius. * Significantly different from SL; $\dagger$ significantly different from $\mathrm{Cy}$ fraction.

acclimation to simulated altitude reveals its ability to affect expression in some but not all tissues examined. Also, past studies have failed to detect MCT 4 in the adult rat heart (31), and it was thought to be absent from this tissue (4). However, we report MCT 4 expression in both SL and HA heart muscle and that this isoform shows significant response to acclimation (Fig. $2 B$ ). The specificity of our antibody has been confirmed (8), but the presence of MCT 4 is perhaps not surprising because cardiac muscles simultaneously take up and release lactate (15). MCT 2 levels were the same in liver before and after acclimation (Fig. 7B). In fact, overall, the liver shows little response to chronic hyp-

Table 2. Occurrence of $A$ and B LDH subunits (\% total) in Cy and Mi fractions of heart and skeletal muscle of rats before and after acclimation to high-altitude hypoxia

\begin{tabular}{cccccc}
\hline \hline & \multicolumn{3}{c}{$\mathrm{A}$} & & \multicolumn{2}{c}{$\mathrm{B}$} \\
\cline { 2 - 3 } \cline { 5 - 6 } Tissue & \multicolumn{1}{c}{$\mathrm{SL}$} & \multicolumn{1}{c}{ HA } & & SL & HA \\
\hline Heart & & & & \\
Cy & $24.2 \pm 0.5$ & $23.5 \pm 0.9$ & & $75.8 \pm 0.5$ & $76.5 \pm 0.9$ \\
Mi & $29.1 \pm 1.2 \dagger$ & $25.0 \pm 1.4^{*}$ & & $70.9 \pm 1.2 \dagger$ & $75.0 \pm 1.4^{*}$ \\
Soleus & & & & \\
Cy & $14.2 \pm 1.9$ & $20.2 \pm 2.2$ & & $85.8 \pm 1.9$ & $79.8 \pm 2.2$ \\
Mi & $24.8 \pm 3.6$ & $27.0 \pm 2.9$ & & $75.3 \pm 3.6$ & $73.0 \pm 2.9$ \\
RG & & & & \\
Cy & $73.9 \pm 2.4$ & $74.1 \pm 1.9$ & & $26.1 \pm 2.4$ & $25.9 \pm 1.9$ \\
Mi & $83.8 \pm 3.0 \dagger$ & $83.6 \pm 2.8 \dagger$ & $16.2 \pm 3.0 \dagger$ & $16.4 \pm 2.8 \dagger$ \\
Plantaris & & & & \\
Cy & $86.0 \pm 2.9$ & $80.6 \pm 2.9$ & & $14.0 \pm 2.9$ & $19.4 \pm 2.9$ \\
Mi & $86.9 \pm 4.6$ & $92.4 \pm 1.8 \dagger$ & $13.1 \pm 4.6$ & $7.6 \pm 1.8 \dagger$ \\
\hline
\end{tabular}

Values are means $\pm \mathrm{SE}$. SL, $n=6$; HA, $n=8$ except for plantaris $(n=3)$. *Significantly different from SL; $\uparrow$ significantly different from Cy fraction. oxia (35). This suggests that the ability of this tissue to transport lactate as a gluconeogenic precursor is not adjusted with this experimental protocol. To date, there have been no studies on the regulatory effects of MCT expression on lactate metabolism. Although past correlative data are intriguing, more detailed measurements of these relationships are warranted.

MCT 1 is highly related to muscle oxidative capacity, and so the decrease in MCT 1 seen in plantaris at first suggests a transition to more fast-twitch myosin isoforms. This hypothesis is not supported by MCT 4, which is also decreased, and LDH, which is unaffected by acclimation.

The lactate shuttle at high altitude. Elements of the cell-cell and intracellular lactate shuttles have been implicated to explain the effects of exercise and hypoxia on lactate metabolism (7). The mechanisms and degree of plasticity of these shuttles, however, are not fully understood. According to the lactate shuttle hypothesis, changes in kinetics should be a product of changes in the components of the shuttle. Here we demonstrate that the components of the shuttle show changes in expression with chronic hypoxia. The effect is tissue specific, and even in the same tissue hypoxia does not result in a coordinated change in all components. Some tissues showed a more synchronous regulation of shuttle components, there being a strong correlation between $\mathrm{Mu} \mathrm{MCT} 1$ and $\mathrm{Cy} \mathrm{LDH}$ expression and a weaker but significant relationship between Mi MCT 1 and mLDH in heart (HA and SL data pooled). In this tissue, which is most affected by hypoxia, coordination between two important components of the shuttle may be necessary to preserve oxidative function. There was a negative correlation between $\mathrm{Mu}$ MCT 1 and Cy LDH in plantaris (Fig. 5). This mixed 

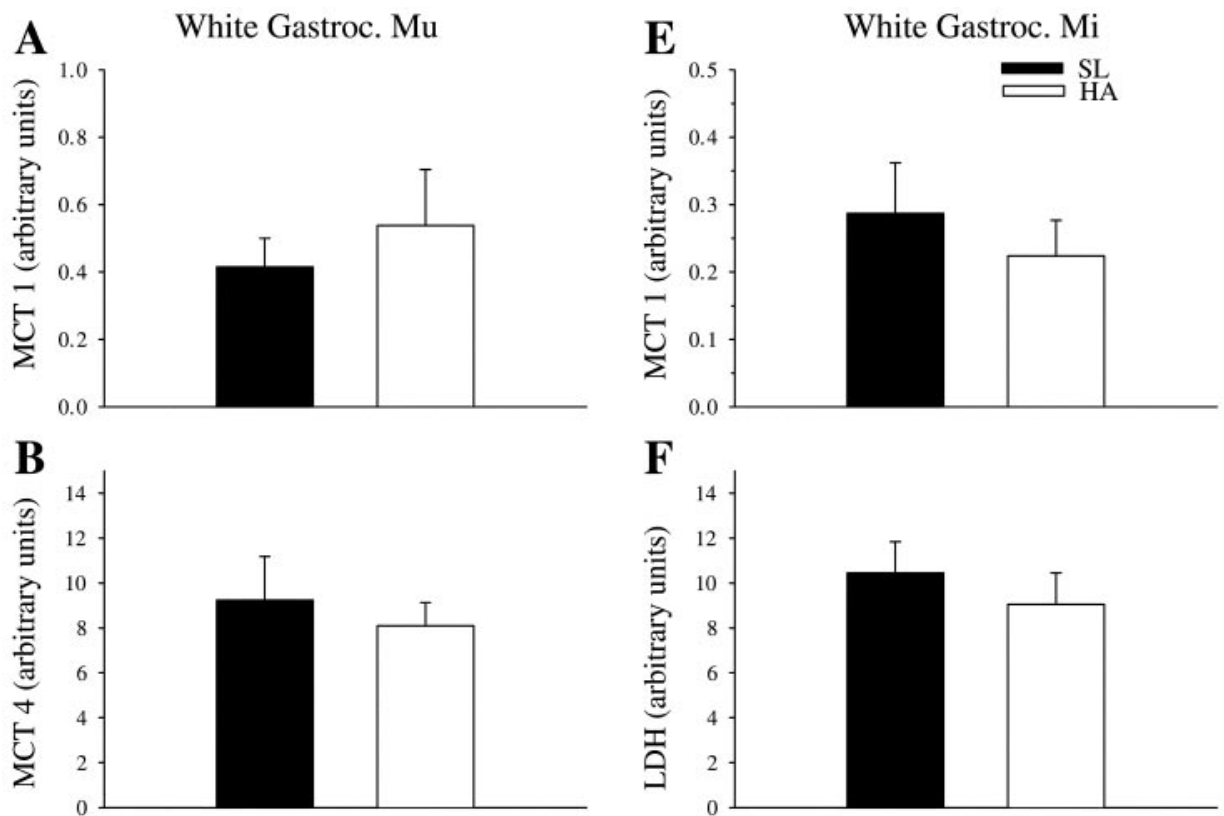

C
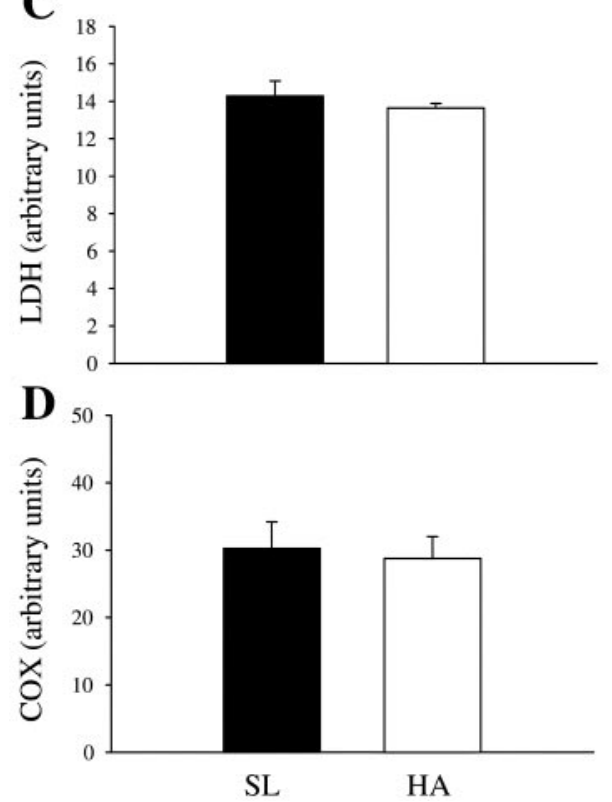

F
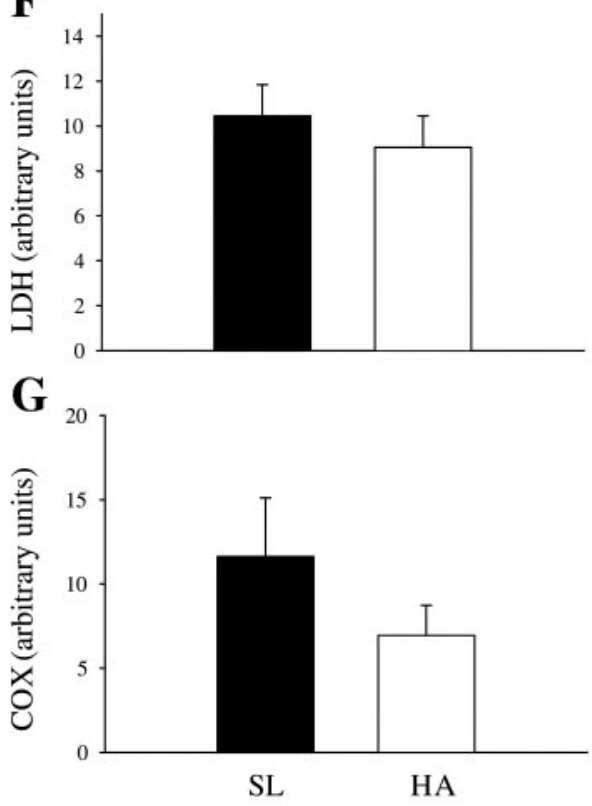

Fig. 6. Expression of MCT 1 ( $A$ and $E$ ), MCT $4(B), \mathrm{LDH}(C$ and $F)$, and $\mathrm{COX}(D$ and $G$ ) in white gastrocnemius $\mathrm{Mu}$ and Mi cell fractions in SL and HA rats; $n=$ 8 for HA and $n=6$ for SL. muscle, high in type II fibers (1), shows a downregulation of MCT 1 and 4 in addition to a decrease in mitochondria density (indexed by COX expression). Surprisingly, there was no decrease of $\mathrm{LDH}$ in $\mathrm{Cy}$ or $\mathrm{Mi}$ fractions (Fig. 5). This most likely reflects the fasttwitch nature of this muscle geared toward glycolysis and net lactate release.

As mentioned above, chronic hypoxia changed the pattern of protein expression in skeletal muscle and heart mitochondria. This novel finding points out that the effects of a systemic environmental stressor can have important subcellular consequences. Here we confirm the presence of $\mathrm{LDH}$ in the mitochondria (10, 19) and show that the most profound effect of chronic hypoxia was seen in the expression of $\mathrm{mLDH}$ (see Figs. $2 F$ and $3 F$ ). Whether there is a resulting change in mitochondrial lactate oxidation rates is unknown. The isolation and respiration of mitochondria from acutely hypoxic and acclimated rats may illuminate putative limiting intracellular steps in lactate oxidation. The differences in $\mathrm{LDH}$ isozyme composition between $\mathrm{Cy}$ and $\mathrm{Mi}$ in most tissues examined rule out contamination of the Mi fraction by cytosolic LDH. The Mi fraction routinely had a greater percentage of $\mathrm{LDH} A$ subunits than the $\mathrm{Cy}$ fraction. This resulted in higher proportions of LDH 5 and $\mathrm{LDH} 4$ in the $\mathrm{Mi}$ of most tissues (Tables 1 and 2).

Lactate metabolism and altitude acclimation. Many hypotheses have been put forward to explain the paradoxical decrease in blood lactate during exercise in the transition from acute to chronic hypoxia (e.g., Refs. 27,32 ). We propose a mechanism by which increased 

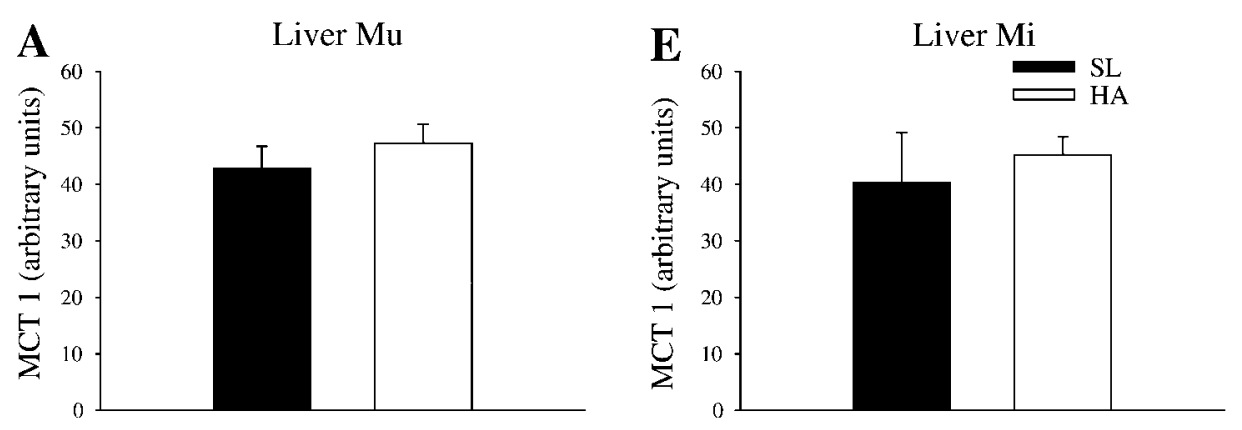

Fig. 7. Expression of MCT 1 ( $A$ and $E)$, MCT $4(B)$, LDH $(C$ and $F)$, and $\operatorname{COX}(D$ and $G$ ) in liver whole tissue $(\mathrm{Mu})$ and $\mathrm{Mi}$ cell fractions in SL and HA rats; $n=8$ for HA and $n=6$ for SL.

\section{B}
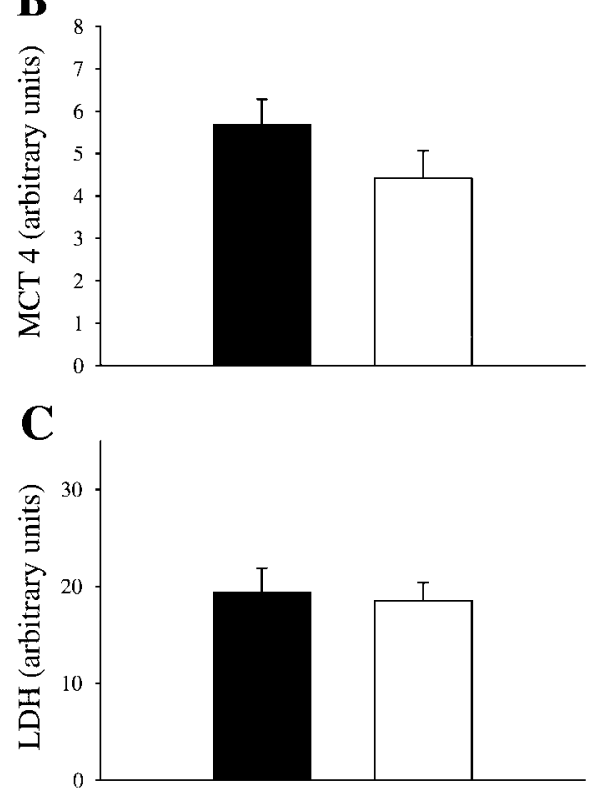

D

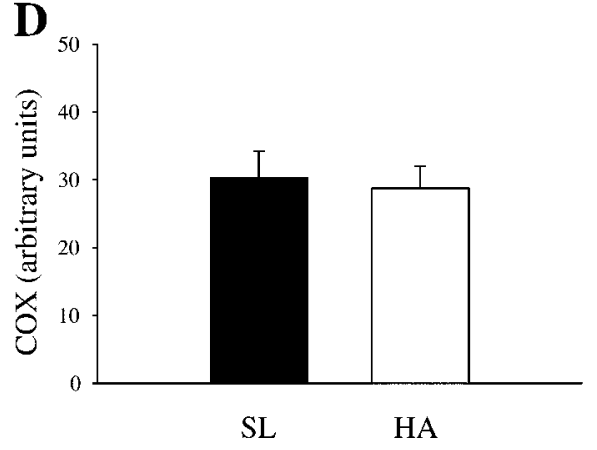

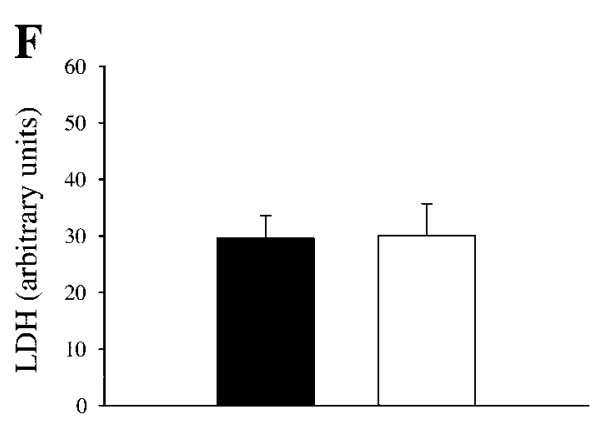

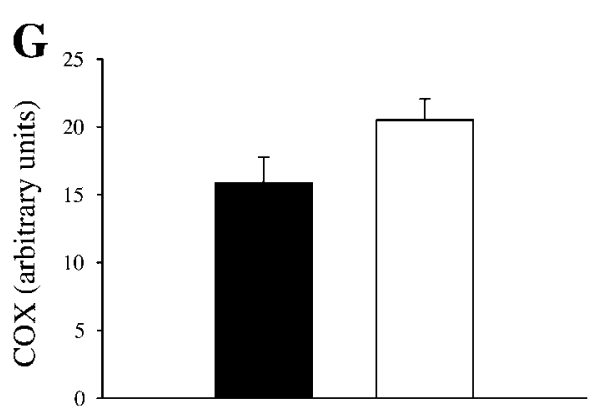

SL transport and oxidation of lactate in skeletal muscle and heart decreases [lactate] $]_{b}$. This hypothesis was born out of the fact that net lactate release is lower and lactate uptake predominates (9) after acclimation compared with acute hypoxia, independent of $\mathrm{O}_{2}$ delivery to muscle (27). Also, after acclimation, muscle lactate concentration during exercise is lower than acute hypoxia values (29), providing further evidence of lower lactate production (27). Similarly, endurance training decreases lactate concentration (12), and this correlates with increases in MCT 1 content in sarcolemmal and mitochondrial membranes (19) and is thought to involve increased utilization by muscles (18). Changes in the components of the cell-cell and intracellular lactate shuttles do not adequately explain all of the observed responses of lactate metabolism to chronic hypoxia. Although arterial lactate concentration theoretically could be reduced by an increase in oxidation in situ, acclimation did not result in a concerted increase in shuttle components. Except in the heart (Fig. 2), most tissues showed no change or even a decrease in the expression in the components of the lactate shuttle. The downregulation of MCT 4 would result in lower [lactate $]_{b}$ as well. Decreases in MCT 4 seen in plantaris muscles of HA (Fig. $4 B$ ) may contribute to lower lactate concentration, but clearly other mechanisms must also come into play (see Ref. 27 for review). It should be noted that decreased rate of appearance of lactate is 
not completely attributed to active muscle. Decreased [lactate $]_{b}$ can be partially explained by decreases in epinephrine with acclimation (27) and lower systemic lactate release. Future experiments integrating changes in lactate transport and oxidation ability with measurements of lactate kinetics during exercise in acutely hypoxic and HA-acclimated rats are clearly warranted.

Conclusions and implications. The underlying mechanisms of the tissue-specific response to chronic hypoxia observed here are not known. The tissue specificity of protein expression in skeletal muscle, in heart, and in liver may result from differences in regional oxygenation. Changes in systemic hypoxia or exercise can lead to regional areas of hypoxia in muscle (45). The patterns of blood flow at rest and during exercise (2) may result in different levels of hypoxia and may be the driving force for changes in hypoxia-induced gene expression, depending on the muscle or other tissues. To date, there has been no study looking at potential promoter regions on the genes encoding MCT 1, 2, or 4 . Also, there are no known promoters or induction factors known to affect the transcription of these genes. Discovery of these factors; how they change with exercise training, hypoxia, or other perturbations; and their tissue specificity are potent areas for future research.

We thank Kalle Magnusson and Lucille Maniti for assistance with the LDH isozyme measurements. We also thank C. Eric Butz for preparing the RBC ghosts.

This research was supported by National Institutes of Health Grants DK-19577 and AR-42906. G. B. McClelland was a recipient of a Natural Sciences and Engineering Research Council of Canada Postdoctoral Fellowship.

\section{REFERENCES}

1. Abdelmalki A, Fimbel S, Mayet-Sornay MH, Sempore B, and Favier R. Aerobic capacity and skeletal muscle properties of normoxic and hypoxic rats in response to training. Pflügers Arch 431: 671-679, 1996.

2. Armstrong RB and Laughlin MH. Metabolic indicators of fibre recruitment in mammalian muscles during locomotion. $J$ Exp Biol 115: 201-213, 1985.

3. Baker SK, McCullagh KA, and Bonen A. Training intensitydependent and tissue-specific increases in lactate uptake and MCT-1 in heart and muscle. J Appl Physiol 84: 987-994, 1998.

4. Bonen A, Miskovic D, Tonouchi M, Lemieux K, Wilson MC, Marette A, and Halestrap AP. Abundance and subcellular distribution of MCT1 and MCT4 in heart and fast-twitch skeletal muscles. Am J Physiol Endocrinol Metab 278: E1067-E1077, 2000.

5. Bonen A, Tonouchi M, Miskovic D, Heddle C, Heikkila JJ, and Halestrap AP. Isoform-specific regulation of the lactate transporters MCT1 and MCT4 by contractile activity. Am J Physiol Endocrinol Metab 279: E1131-E1138, 2000.

6. Brooks GA. The lactate shuttle during exercise and recovery. Med Sci Sports Exerc 18: 360-368, 1986.

7. Brooks GA. Are arterial, muscle and working limb lactate exchange data obtained on men at altitude consistent with the hypothesis of an intracellular lactate shuttle? In: Hypoxia: Into the Next Millennium, edited by Roach RC, Wagner PD, and Hackett PH. New York: Kluwer Academic/Plenum, 1999, p. 185204.

8. Brooks GA, Brown MA, Butz CE, Sicurello JP, and Dubouchaud H. Cardiac and skeletal muscle mitochondria have a monocarboxylate transporter MCT1. J Appl Physiol 87: 1713-1718, 1999.
9. Brooks GA, Wolfel EE, Groves BM, Bender PR, Butterfield GE, Cymerman A, Mazzeo RS, Sutton JR, Wolfe RR, and Reeves JT. Muscle accounts for glucose disposal but not blood lactate appearance during exercise after acclimation to $4,300 \mathrm{~m}$. J Appl Physiol 72: 2435-2445, 1992.

10. Brooks GA, Dubouchaud H, Brown M, Sicurello JP, and Butz CE. Role of mitochondrial lactate dehydrogenase and lactate oxidation in the intracellular lactate shuttle. Proc Natl Acad Sci USA 96: 1129-1134, 1999.

11. Brooks GA and Gaesser GA. End points of lactate and glucose metabolism after exhausting exercise. J Appl Physiol 49: 10571069, 1980.

12. Brooks GB. Current concepts in lactate exchange. Med Sci Sports Exerc 23: 895-906, 1991.

13. Campbell WG, Gordon SE, Carlson CJ, Pattison JS, Hamilton MT, and Booth FW. Differential global gene expression in red and white skeletal muscle. Am J Physiol Cell Physiol 280: C763-C768, 2001.

14. Cerretelli $\mathbf{P}$ and Hoppeler H. Morphology and metabolic response to chronic hypoxia: the muscle system. In: Handbook of Physiology. Environmental Physiology. Bethesda, MD: Am. Physiol. Soc., 1996, sect. 4, vol. II, chapt. 50, p. 1155-1181.

15. Chatham JC, Des Rosiers C, and Forder JR. Evidence of separate pathways for glycolytic lactate production and metabolism of exogenous lactate in the isolated perfused rat heart. Am J Physiol Endocrinol Metab 281: E794-E802, 2001.

16. Chavez JC, Agani F, Pichuile P, and Lamanna JC. Expression of hypoxia-inducible factor- $1 \alpha$ in the brain of rats during chronic hypoxia. J Appl Physiol 89: 1937-1942, 2000.

17. Dimmer KS, Friedrich B, Lang F, Deitmer JW, and Broer S. The low-affinity monocarboxylate transporter MCT4 is adapted to the export of lactate in highly glycolytic cells. Biochem J 350: 219-227, 2000.

18. Donovan CM and Brooks GA. Endurance training affects lactate clearance, not lactate production. Am J Physiol Endocrinol Metab 244: E83-E92, 1983.

19. Dubouchaud H, Butterfield GE, Wolfel EE, Bergman BC, and Brooks GA. Endurance training, expression and physiology of LDH, MCT1, and MCT4 in human skeletal muscle. Am J Physiol Endocrinol Metab 278: E571-E579, 2000.

20. Dubouchaud H, Granier P, Mercier J, Le Peuch C, and Prefaut C. Lactate uptake by skeletal muscle sarcolemmal vesicles decreases after $4 \mathrm{wk}$ of hindlimb unweighting in rats. J Appl Physiol 80: 416-421, 1996.

21. Ebert BL, Gleadle JM, O'Rourke JF, Bartlett SM, Poulton J, and Ratcliffe PJ. Isozyme-specific regulation of genes involved in energy metabolism by hypoxia: similarities with the regulation of erythropoietin. Biochem $J$ 313: 809-814, 1996.

22. Edwards HT. Lactic acid in rest and work at high altitude. Am J Physiol 116: 367-375, 1936.

23. Fandrey J. Hypoxia-inducible gene expression. Respir Physiol 101: 1-10, 1995.

24. Favero TG, Stavrianeas S, and Klug GA. Training-induced alterations in lactate dehydrogenase reaction kinetics in rats: a re-examination. Exp Physiol 84: 989-998, 1999.

25. Field ML, Clark JF, Henderson C, Seymour AM, and Radda GK. Alterations in the myocardial creatine kinase system during chronic anaemic hypoxia. Cardiovasc Res 28: 86-91, 1994.

26. Firth JD, Elbert BL, and Ratcliffe PJ. Hypoxic regulation of lactate dehydrogenase A. J Biol Chem 270: 21021-21027, 1995.

27. Gladden LB. Lactate transport and exchange during exercise. In: Handbook of Physiology. Exercise: Regulation and Integration of Multiple Systems. Bethesda, MD: Am. Physiol. Soc., 1996, sect. 12 , chapt. 14 , p. $614-648$.

28. Green HJ, Sutton JR, Cymerman A, Young PM, and Houston S. Operation Everest II: adaptations in human skeletal muscle. J Appl Physiol 66: 2454-2461, 1989.

29. Green HJ, Sutton J, Young P, Cymerman A, and Houston CS. Operation Everest II: muscle energetics during maximal exhaustive exercise. J Appl Physiol 66: 142-150, 1989.

30. Halestrap AP and Prince NT. The proton-linked monocarboxylate transporter (MCT) family: structure, function and regulation. Biochem J 343: 281-299, 1999. 
31. Hatta H, Tonouchi M, Miskovic D, Wang Y, Heikkila JJ, and Bonen A. Tissue-specific and isoform-specific changes in MCT1 and MCT4 in heart and soleus muscle during a 1-yr period. Am J Physiol Endocrinol Metab 281: E749-E756, 2001.

32. Hochachka PW. The lactate paradox: analysis of underlying mechanisms. Ann Sport Med 4: 184-188, 1988.

33. Hochachka PW, Stanley C, Merkt J, and Sumar-Kalinowski J. Metabolic meaning of elevated levels of oxidative enzymes in high altitude adapted animals: an interpretive hypothesis. Respir Physiol 52: 303-313, 1982.

34. Hood DA. Invited review: contractile activity-induced mitochondrial biogenesis in skeletal muscle. J Appl Physiol 90: 11371157, 2001.

35. Kennedy SL, Stanley WC, Panchal AR, and Mazzeo RS. Alterations in enzymes involved in fat metabolism after acute and chronic altitude exposure. J Appl Physiol 90: 17-22, 2001.

36. Kitaura T, Tsunekawa N, and Hatta H. Decreased monocarboxylate transporter 1 in rat soleus and EDL muscles exposed to clenbuterol. J Appl Physiol 91: 85-90, 2001.

37. Mazzeo RS, Brooks GA, Schoeller DA, and Budinger TF. Disposal of blood $\left[1-{ }^{13} \mathrm{C}\right]$ lactate in humans during rest and exercise. J Appl Physiol 60: 232-241, 1986.

38. McClelland GB, Hochachka PW, and Weber JM. Carbohydrate utilization during exercise after high-altitude acclimation: a new perspective. Proc Natl Acad Sci USA 95: 10288-10293, 1998.

39. McClelland GB, Hochachka PW, Reidy S, and Weber JM. High-altitude acclimation increases the triacylglycerol/fatty acid cycle at rest and during exercise. Am J Physiol Endocrinol Metab 281: E537-E544, 2001.

40. McCullagh KL, Poole RC, Halestrap AP, Tipton KF, O'Brien M, and Bonen A. Chronic electrical stimulation increases MCT1 and lactate uptake in red and white muscle. Am $J$ Physiol Endocrinol Metab 273: E239-E246, 1997.

41. Olfert IM, Breen EC, Mathieu-Costello O, and Wagner PD. Chronic hypoxia attenuates resting and exercise-induced VEGF, flt-1, and flk-1 mRNA levels in skeletal muscle. J Appl Physiol 90: 1532-1538, 2001

42. Pellerin L, Pellegri G, Bittar PG, Charnay Y, Bouras C, Martin JL, Stella N, and Magistretti PJ. Evidence supporting the existence of an activity-dependent astrocyte-neuron lactate shuttle. Dev Neurosci 20: 291-299, 1998.

43. Semenza G, Roth P, Fang H, and Wang G. Transcriptional regulation of genes encoding glycolytic enzymes by hypoxiainducible factor 1. J Biol Chem 269: 23757-23763, 1994.

44. Semenza GL. HIF-1: mediator of physiological and pathophysiological responses to hypoxia. J Appl Physiol 88: 1474-1480, 2000.

45. Sieck GC and Johnson BD. Metabolic and structural alterations in skeletal muscle with hypoxia. In: Tissue Oxygen Deprivation: From Molecular to Integrated Function, edited by Haddad GG and Lister G. New York: Dekker, 1996, p. 779-827.

46. Szczesna-Kaczmarek A. L-Lactate oxidation by skeletal muscle mitochondria. Int $J$ Biochem 22: 617-620, 1990. 